\title{
The Economic Burden of Cancer in Korea in 2009
}

\author{
So Young Kim ${ }^{1,2}$ Jong-Hyock Park ${ }^{2,3 *}$, Kyoung Hee Kang ${ }^{2}$, Inuk Hwang ${ }^{2}$, Hyung \\ Kook Yang', Young-Joo Won², Hong-Gwan Seo², Dukhyoung Lee ${ }^{2}$, Seok-Jun \\ Yoon $^{4}$
}

\begin{abstract}
Background: Cancer imposes a significant economic burden on individuals, families and society. The purpose of this study was to estimate the economic burden of cancer using the healthcare claims and cancer registry data in Korea in 2009. Materials and Methods: The economic burden of cancer was estimated using the prevalence data where patients were identified in the Korean Central Cancer Registry. We estimated the medical, non-medical, morbidity and mortality cost due to lost productivity. Medical costs were calculated using the healthcare claims data obtained from the Korean National Health Insurance (KNHI) Corporation. Non-medical costs included the cost of transportation to visit health providers, costs associated with caregiving for cancer patients, and costs for complementary and alternative medicine (CAM). Data acquired from the Korean National Statistics Office and Ministry of Labor were used to calculate the life expectancy at the time of death, age- and gender-specific wages on average, adjusted for unemployment and labor force participation rate. Sensitivity analysis was performed to derive the current value of foregone future earnings due to premature death, discounted at 3\% and 5\%. Results: In 2009, estimated total economic cost of cancer amounted to $\$ 17.3$ billion at a 3\% discount rate. Medical care accounted for $28.3 \%$ of total costs, followed by non-medical (17.2\%), morbidity (24.2\%) and mortality (30.3\%) costs. Conclusions: Given that the direct medical cost sharply increased over the last decade, we must strive to construct a sustainable health care system that provides better care while lowering the cost. In addition, a comprehensive cancer survivorship policy aimed at lower caregiving cost and higher rate of return to work has become more important than previously considered.
\end{abstract}

Keywords: Cost analysis - cost of illness - cancer - health care costs - Korea

Asian Pac J Cancer Prev, 16 (3), 1295-1301

\section{Introduction}

Cancer is currently the leading cause of death in developed countries (Jemal et al., 2011). In 2009, 69,780 cancer deaths were reported, accounting for $28.3 \%$ of all deaths in Korea (Jung et al., 2012). With the significant contribution of advances in modern medicine to the survival rates of cancer patients and aging of the population, the cancer burden in a society is expected to increase substantially in the future. To prioritize and allocate resources for cancer control efforts, it is necessary to quantify the cancer burden from the societal perspective. In turn, socioeconomic cost of cancer is consisted of direct costs (medical or non-medical) and indirect costs due to morbidity or premature mortality.

In Korea, Cancer already accounts for a significant portion of the national medical cost; the Korean National Health Insurance (KNHI) Corporation estimates that its insurer payments in 2009 were accounted for $12 \%$ of total expenditures (KNHIC, 2009). Non-medical costs are represented by but not limited to the relatively high level of both objective (e.g., patient hospitalizations, providing transportation) and subjective burden (e.g., emotional trauma, worry, reduced caregiver wellbeing) that family caregivers experience (Shin et al., 2012; Turkoglu and Kilic, 2012; Kim et al., 2013). For example, cancer forces some patients to give up their work either temporarily or permanently, which lead to the health-related impact of cancer on society (You et al., 2013; Hanly and Sharp, 2014). Therefore, it is crucial to estimate the burden of cancer for a representative patients group using a nationwide database to accurately picture the implications of cancer care cost in Korea. Until now, nation-wide studies of the economic burden of cancer care were conducted in 2002 and 2005 in Korea (Kim et al., 2008; Kim et al., 2009). Yet, more recent studies focused on individual cancer sites (Tachfouti et al., 2012; Yang, 2013; Byun et al., 2014; Wissinger et al., 2014) or specific components of the cancer care cost (Choi et al., 2014; Hanly and Sharp, 2014; Wissinger et al., 2014), thus failing to yield a gross estimate and the future direction of the cancer burden. In this study, we

${ }^{1}$ Office for Public Healthcare, Chungbuk National University Hospital, ${ }^{3}$ College of Medicine, Chungbuk National University, Cheong$j u,{ }^{2}$ National Cancer Control Institute, National Cancer Center, Goyang, ${ }^{4}$ Department of Preventive Medicine, Korea University College of Medicine, Seoul, Korea*For correspondence: jonghyock@chungbuk.ac.kr, jonghyock@gmail.com 
aim to derive the overall economic burden of cancer and examine the changing patterns of direct and indirect costs of cancer care, using the previous nationwide studies as references. To enhance comparability between studies, we used similar framework as previous studies (Kim et al., 2008; Kim et al., 2009). Documenting changing economic impact of cancer can assist setting the priority in health care research and delivery including prevention, diagnosis, and treatment of cancer.

\section{Materials and Methods}

\section{Data source and study patient identification}

The two major data sources used were the Korean Central Cancer Registry (KCCR) and the Korean National Health Insurance (KNHI) claims database. KCCR is a nationwide cancer registry program sponsored by the government in which more than 180 hospitals participate. The completeness of registration for 2009 was estimated to be $97.2 \%$ of cancer cases (Jung et al., 2012). For each patient, the KCCR included information on gender, date of diagnosis, cancer site, histology, and the Surveillance, Epidemiology, and End Results (SEER) summary stage, date of death, and so forth. Among 878,834 cancer cases in the KCCR in 2009, those with medical claims history ( $\mathrm{n}=$ $861,132)$ in 2009 were selected. Patients with incomplete socio-demographic information $(n=270)$ were excluded, leaving 860,862 patients in the study. Then the study subjects were matched with the KNHI claims. Since medical providers are paid by the KNHI Corporation on Fee-for-service basis in Korea, vast information necessary for reimbursement of the medical claims are stored in the KNHI claims database. This data include patients' socio-demographic (such as sex, age, residential area, disease code, costs incurred), and clinical information (a detailed list of diagnostic tests, procedures, hospital length of stay and outpatient visits by type of medical service, prescription provided).

\section{Cost classification and definition}

In line with previous nation-wide studies (Kim et al., 2008; Kim et al., 2009), the cost of cancer was computed following the prevalence-based approach, which estimates the economic burden in year 2009 resulted from the prevalence of cancer. For this study, we adopted a societal perspective to include both direct costs (medical care cost, non-medical cost), and indirect costs (morbidity cost, mortality cost) of cancer. Medical care costs are expenditures spent on the medical procedures and services associated with treatment performed in hospital or clinic; this includes costs for hospitalization, outpatient visits and prescription drugs. Because administrative claims database records the cost of billed services only, fee for non-insured services paid out-of-pockets are estimated based on the survey result that is annually conducted by KNHI Corporation (KNIHC, 2010). Non-medical costs include transportation cost to visit healthcare providers, cost associated with caregiving for cancer patients, and cost for complementary and alternative medicine (CAM). A previous study in Korea of those employed showed that $26 \%$ lose their job within the first year of cancer diagnosis
(Park et al., 2008). For patients who avoid the job loss, reducing work hours due to treatment is common, which result in earning less. In addition, family caregivers may also have to reduce paid work to support cancer patients on management of treatment schedule, accompanying hospital, monitoring health status of patient, and so forth. A prior study of 89 caregivers of female patients with advanced breast cancer showed that $69 \%$ of employed caregivers reported some form of adverse impact on work. Furthermore, entering the terminal stage, $77 \%$ reported missing work because of caregiving responsibilities (Grunfeld et al., 2004). Thus, morbidity costs are defined as the time and economic output lost from daily activities as well as work as a result of a disease and its treatment (Yabroff et al., 2004). Mortality costs are expressed as the present value of future productivity losses due to premature death (Luengo-Fernandez et al., 2013). Other components of cancer burden that are intangible or psychosocial costs (e.g., pain, grief, well-being) are not considered in this study. We were able to estimate the overall economic burden of cancer by combining the medical, non-medical, morbidity, and mortality cost. All costs estimated, are represented in 2009 US dollars using an exchange rate of 1,276 Korean Won to 1 US dollar, which was the annual exchange rate in 2009.

\section{Cost estimation}

Medical care cost was estimated using the health claims data from the KNHI Corporation. The ceiling on cumulative out-of-pocket payments was also applied for insured services. Due to limited benefits coverage, patients pay copayment for insured services and in full for non-insured services. As claims data included the cost for insurance-covered services only, it was necessary to identify the proportion of non-insured services among all services utilized to estimate the total medical cost of cancer. We applied the coverage rate for inpatient and outpatient services measured in the annual studies of non-covered service (KNIHC, 2010).

Transportation costs to health care providers were calculated on the basis of inpatient and outpatient hospital visits where an average one way transportation cost of \$17.12 and \$3.86 are applied for inpatient and outpatient visits, respectively (KCDC, 2009). In the calculation, one caregiver was included, assuming at least a caregiver would accompany hospital visits. Fee for caregiving services was estimated based on the individual annual inpatient days and an average daily wage of $\$ 43$ for a professional caregiver service (KPHS, 2009). Lastly, the average cost of CAM $(\$ 1,136)$ was applied for the cost of CAM, which is value used in previous study (Kim et al., 2009).

We used the human capital approach to estimate the value of lost productivity resulting from morbidity, disability, and premature death, valued at the market wage (Drummond et al., 2005). Losses due to morbidity were computed separately for those who 1) reduced working hours due to cancer experience 2) lost their job due to cancer experience and 3) persons outside of the labor market (Kim et al., 2008). Morbidity cost for days lost from work due to cancer treatment is valued using 
the average age- and gender-specific daily wage. Lost work days are calculated by summing the number of hospital inpatient days and half of outpatient visit days. For individuals who lost the job due to cancer, age- and gender-specific estimates of the average annual earnings were applied to determine morbidity. Finally, morbidity costs for those outside the labor market were valued by multiplying the average age- and gender-specific daily wages by number of days lost. All are aggregated to derive the overall morbidity cost of cancer.

We estimated the mortality costs using the following method. First, number of age and sex-specific cancer deaths in 2009 was used to predict the potential working years lost at death. Then we applied the age and sex specific probability of employment to the working years lost to derive the overall mortality cost. This method of estimating the mortality cost takes into consideration the life expectancy for different age and sex groups, changing pattern of earnings at different ages, employment rates, and appropriate discount rate to convert the stream of earnings into its present worth (Kim et al., 2008). Life expectancy at the age of death was obtained from the Korean Statistical Information System in 2009. And the data on percentage of the population with earnings and the annual average earnings by sex and age in 2009 were obtained from the 2009 Labor statistics of Korea (Ministry of Labor, 2009). Annual discount rates of 3\% and 5\%
Aspects of the Economic Burden of Cancer in Korea in 2009

were applied.

In addition, as prior studies (Kim et al., 2008; Hanly and Sharp, 2014), we disregarded any deaths in children $(<15)$ and 64 years and over since Korean workers generally retire after 65 and do not earn a wage. However, it is inaccurate and unethical to place no economic value on a person's life after 65 . Therefore, the average annual earnings for the age group between 60 and 64 were used as a proxy measure for the economic value of the life after age 65 , following prior study (Kim et al., 2008). For the purpose of sensitivity analysis, the premature death cost was recalculated by applying 50\% (instead of 100\%) of the average annual earnings for those aged between 60 and 64 years. Finally, to estimate the value of a caregiver's time spent to accompany a cancer patient to an outpatient visit, we multiplied the annual outpatient visits by an average half day wage. This assumed that half of the daily working hours were spent for an outpatient visit. The average hourly wage used was $\$ 9.76$ (Ministry of Labor, 2009).

\section{Results}

\section{Cancer prevalence}

In 2009, a total of 403,342 men and 457,520 women with cancer were identified (Table 1). Among the patients, stomach cancer was the most prevalent (18.0\%), followed by thyroid cancer $(15.9 \%)$, colorectal cancer $(13.8 \%)$,

Table 1. Number of Patients by Sex, Age and Cancer Site (Unit: Person,\%)

\begin{tabular}{|c|c|c|c|c|c|c|c|c|c|c|c|c|c|c|}
\hline \multirow[t]{2}{*}{ Cancer Site } & \multicolumn{2}{|c|}{ Total } & \multicolumn{2}{|c|}{ Male } & \multicolumn{2}{|c|}{ Female } & \multicolumn{8}{|c|}{$\operatorname{Age}(\%)$} \\
\hline & $\mathrm{N}$ & $\%$ & $\mathrm{~N}$ & $\%$ & $\mathrm{~N}$ & $\%$ & $<20$ & $20-29$ & $30-39$ & $40-49$ & $50-59$ & $60-69$ & $70-79$ & $80 \geq$ \\
\hline 16) & 155,400 & 18.0 & 103,164 & 25.6 & 52,236 & 11.4 & 0.3 & 3.2 & 8.5 & 12.9 & 16.6 & 22.0 & 23.5 & 19.4 \\
\hline Lur &, 319 & 5.7 & 34,027 & 8.4 & 15,292 & 3.3 & 0.4 & 0.8 & 1.0 & 1.9 & 4.0 & 7.5 & 9.4 & 9.8 \\
\hline Liver(C22) & 48,417 & 5.6 & 36,453 & 9.0 & 11,964 & 2.6 & 2.0 & 0.9 & 1.8 & 4.3 & 7.0 & 7.1 & 5.4 & 4.4 \\
\hline Colon and rectum $(\mathrm{C} 18-\mathrm{C}$ & 119,134 & 13.8 & 69,968 & 17.3 & 49,166 & 10.7 & 0.3 & 2.8 & 4.8 & 7.7 & 12.4 & 17.0 & 18.7 & 20.0 \\
\hline Breast(C50) & 88,013 & 10.2 & 399 & 0.1 & 87,614 & 19.1 & 0.1 & 3.4 & 13.1 & 20.1 & 15.1 & 7.1 & 3.6 & 2.5 \\
\hline Cervi & 34,207 & 4.0 & - & 0.0 & 34,199 & 7.5 & 0.1 & 2.4 & 5.6 & 6.5 & 4.6 & 3.1 & 2.7 & 2.4 \\
\hline Thyroid (C73) & 136,949 & 15.9 & 19,930 & 4.9 & 117,019 & 25.6 & 4.0 & 38.9 & 42.7 & 29.1 & 19.5 & 9.7 & 4.3 & 2.1 \\
\hline Gallb & 13,324 & 1.5 & 6,708 & 1.7 & 6,616 & 1.4 & 0.0 & 0.1 & 0.2 & 0.5 & 1.0 & 1.9 & 2.5 & 3.4 \\
\hline Panc & 442 & 1.0 & 4,682 & 1.2 & 3,760 & 0.8 & 0.3 & 0.3 & 0.3 & 0.4 & 0.8 & 1.1 & 1.5 & 1.9 \\
\hline Blad & 19,903 & 2.3 & 16,079 & 4.0 & 3,824 & 0.8 & 0.3 & 0.4 & 0.6 & 0.8 & 1.5 & 2.6 & 3.8 & 5.3 \\
\hline Pros & 29,749 & 3.5 & 29,749 & 7.4 & , & 0.0 & 0.0 & 0.0 & 0.0 & 0.1 & 1.0 & 4.2 & 7.5 & 9.4 \\
\hline Kidr & 17,531 & 2.0 & 11,789 & 2.9 & 5,742 & 1.3 & 3.9 & 1.1 & 1.6 & 1.9 & 2.3 & 2.2 & 2.0 & 1.5 \\
\hline Esol & 6,473 & 0.8 & 5,883 & 1.5 & 590 & 0.1 & 0.0 & 0.0 & 0.0 & 0.2 & 0.5 & 1.1 & 1.3 & 0.9 \\
\hline Ova & 10,594 & 1.2 & 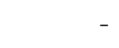 & 0.0 & 10,592 & 2.3 & 3.1 & 5.4 & 2.2 & 1.6 & 1.4 & 0.9 & 0.6 & 0.5 \\
\hline Let & 12,126 & 1.4 & 6,681 & 1.7 & 5,445 & 1.2 & 31.6 & 8.0 & 2.6 & 1.4 & 0.9 & 0.7 & 0.6 & 0.5 \\
\hline Ora & 085 & 0.8 & 4,274 & 1.1 & 2,811 & 0.6 & 0.9 & 1.7 & 1.0 & 0.8 & 0.8 & 0.8 & 0.8 & 0.8 \\
\hline Lar & 319 & 0.8 & 6,384 & 1.6 & 435 & 0.1 & 0.0 & 0.0 & 0.1 & 0.2 & 0.6 & 1.2 & 1.2 & 1.0 \\
\hline Melanoma of skin(C43) & 2,025 & 0.2 & 915 & 0.2 & ,110 & 0.2 & 0.3 & 0.3 & 0.2 & 0.2 & 0.2 & 0.2 & 0.3 & 0.3 \\
\hline \multicolumn{15}{|c|}{ Brain and central nervous system (C70-C72) } \\
\hline & 7,381 & 0.9 & 3,875 & 1.0 & 3,506 & 0.8 & 12.8 & 5.4 & 1.8 & 1.0 & 0.6 & 0.5 & 0.4 & 0.4 \\
\hline \multicolumn{15}{|c|}{ Non-Hodgkin lymphoma (C82-C85;C96) } \\
\hline & 18,744 & 2.2 & 10,291 & 2.6 & 8,453 & 1.8 & 9.9 & 6.8 & 3.1 & 2.2 & 2.0 & 1.9 & 1.8 & 1.5 \\
\hline 110 & 1,390 & 0.2 & 881 & 0.2 & 509 & 0.1 & 1.4 & 2.1 & 0.5 & 0.1 & 0.1 & 0.1 & 0.1 & 0.0 \\
\hline Mult & 3,322 & 0.4 & 1,778 & 0.4 & 1,544 & 0.3 & 0.0 & 0.1 & 0.1 & 0.2 & 0.4 & 0.5 & 0.5 & 0.4 \\
\hline Tes & 1,467 & 0.2 & 1,466 & 0.4 & 1 & 0.0 & 2.2 & 2.1 & 0.9 & 0.2 & 0.1 & 0.0 & 0.0 & 0.0 \\
\hline & 9,794 & 1.1 & 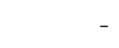 & 0.0 & 9,793 & 2.1 & 0.0 & 0.6 & 1.3 & 1.4 & 1.9 & 1.1 & 0.5 & 0.3 \\
\hline Nasopharynx (C11) & 2,264 & 0.3 & 1,620 & 0.4 & 644 & 0.1 & 0.4 & 0.6 & 0.3 & 0.4 & 0.3 & 0.2 & 0.1 & 0.1 \\
\hline \multicolumn{15}{|l|}{ Other pharynx } \\
\hline $2-(14)$ & 935 & 0.3 & 2,574 & 0.6 & 361 & 0.1 & 0.1 & 0.0 & 0.1 & 0.2 & 0.4 & 0.5 & 0.4 & 0.3 \\
\hline & 055 & 5.6 & 23,761 & 5.9 & 24,294 & 5.3 & 25.7 & 12.3 & 5.4 & 3.8 & 3.9 & 4.9 & 6.5 & 10.8 \\
\hline Total & 860,862 & 100 & 403,342 & 100 & 457,520 & 100 & 100 & 100 & 100 & 100 & 100 & 100 & 100 & 100 \\
\hline
\end{tabular}


breast cancer $(10.2 \%)$, lung cancer $(5.7 \%)$ and liver cancer $(5.6 \%)$. Examining the patients by age revealed that leukemia, thyroid, and gastric cancer were the most prevalent in the age groups of under years 20, 20-50, 60 and older, respectively.

\section{Medical and non-medical costs}

The total medical expenditure for cancer in Korea in 2009 amounted to $\$ 4,900$ million of which the National Health Insurance paid $67.8 \%$ (Table 2). Inpatient services accounted for $\$ 2,953$ million, or $60.3 \%$ of the total medical costs. And outpatient services amounted to $\$ 1,390$ million, followed by the prescription drug cost of $\$ 557$ million.

Distribution of the total medical cost by site of cancer showed that colorectal cancer incurred the highest cost
(\$703 million) (Table 3). It is followed by stomach cancer (\$677 million), lung cancer (\$520 million), liver cancer (\$473 million) and breast cancer (\$407 million). Nonmedical cost amounted to $\$ 2,973$ million, falling short of the medical cost of $\$ 4,900$ million (Table 3). The highest non-medical cost occurred for individuals with stomach cancer ( $\$ 518$ million), followed by colorectal cancer $(\$ 426$ million), thyroid cancer ( $\$ 406$ million), breast cancer (\$275 million), and lung cancer (\$212 million).

\section{Morbidity costs and mortality costs}

Table 4 shows the morbidity cost of cancer, defined by the value of lost earnings and the opportunity cost of lost productivity among the employed patients as well as those unable to work due to cancer related reasons.

Table 2. Medical Care Expenditures for Cancer by Type of Medical Service

\begin{tabular}{|c|c|c|c|c|c|c|c|c|}
\hline \multirow[b]{2}{*}{ Type of service } & \multicolumn{2}{|c|}{ Insurer payment } & \multicolumn{2}{|c|}{ Co-insurance } & \multicolumn{2}{|c|}{ Not-covered } & \multicolumn{2}{|c|}{ Total } \\
\hline & $\begin{array}{c}\text { Per patient } \\
(\$)\end{array}$ & $\begin{array}{c}\text { Total } \\
(\$ \text { millions })\end{array}$ & $\begin{array}{c}\text { Per patient } \\
(\$)\end{array}$ & $\begin{array}{c}\text { Total } \\
(\$ \text { millions })\end{array}$ & $\begin{array}{c}\text { Per patient } \\
(\$)\end{array}$ & $\begin{array}{c}\text { Total } \\
(\$ \text { millions })\end{array}$ & $\begin{array}{c}\text { Per patient } \\
(\$)\end{array}$ & $\begin{array}{c}\text { Total } \\
(\$ \text { millions })\end{array}$ \\
\hline All service & 3,857 & 3,320 & 554 & 477 & 1,274 & 1,097 & 5,692 & 4,900 \\
\hline Inpatient & 2,175 & 1,872 & 234 & 201 & 1,019 & 877 & 3,431 & 2,953 \\
\hline Outpatient & 1,145 & 986 & 212 & 182 & 255 & 220 & 1,614 & 1,390 \\
\hline Prescription drugs & 537 & 462 & 108 & 93 & - & - & 647 & 557 \\
\hline
\end{tabular}

Table 3. Medical and Non-medical Costs According to Cancer Site

\begin{tabular}{|c|c|c|c|c|}
\hline \multirow[b]{2}{*}{ Cancer Site } & \multicolumn{2}{|c|}{ Medical care costs } & \multicolumn{2}{|c|}{ Non-medical costs* } \\
\hline & $\begin{array}{c}\text { Per patient } \\
\text { (\$) }\end{array}$ & $\begin{array}{l}\mathrm{t} \text { Total } \mathrm{Pe} \\
(\$ \text { millions })\end{array}$ & $\begin{array}{l}\text { Per patien } \\
\text { (\$) }\end{array}$ & $\begin{array}{l}\text { Tt } \text { Total } \\
\text { (\$ millions) }\end{array}$ \\
\hline Stomach & 4,359 & 677 & 3,336 & 518 \\
\hline Lung & 10,534 & 520 & 4,291 & 212 \\
\hline Liver & 9,769 & 473 & 3,802 & 184 \\
\hline Colon and rectum & 5,904 & 703 & 3,574 & 426 \\
\hline Breast & 4,626 & 407 & 3,128 & 275 \\
\hline Cervix uteri & 3,418 & 117 & 3,129 & 107 \\
\hline Thyroid & 2,488 & 341 & 2,968 & 406 \\
\hline Gallbladder & 8,336 & 111 & 4,165 & 55 \\
\hline Pancreas & 10,769 & 91 & 4,490 & 38 \\
\hline Bladder & 4,394 & 87 & 3,556 & 71 \\
\hline Prostate & 5,423 & 161 & 3,906 & 116 \\
\hline Kidney & 5,207 & 91 & 3,345 & 59 \\
\hline Esophagus & 9,079 & 59 & 4,166 & 27 \\
\hline Ovary & 7,218 & 76 & 3,538 & 37 \\
\hline Leukemia & 18,613 & 226 & 3,487 & 42 \\
\hline Oral cavity & 5,112 & 36 & 3,416 & 24 \\
\hline Larynx & 4,738 & 32 & 3,597 & 25 \\
\hline Melanoma of skin & 6,079 & 12 & 3,840 & 8 \\
\hline \multicolumn{5}{|c|}{ Brain and central nervous system } \\
\hline & 10,493 & 77 & 3,935 & 29 \\
\hline \multicolumn{5}{|c|}{ Non-Hodgkin lymphoma } \\
\hline & 8,435 & 158 & 3,456 & 65 \\
\hline Hodgkin disease & 6,144 & 9 & 2,873 & 4 \\
\hline Multiple myeloma & 17,376 & 58 & 4,799 & 16 \\
\hline Testis & 2,601 & 4 & 2,078 & 3 \\
\hline Corpus uteri & 3,875 & 38 & 3,185 & 31 \\
\hline Nasopharynx & 6,515 & 15 & 3,791 & 9 \\
\hline Other pharynx & 8,188 & 24 & 4,078 & 12 \\
\hline Others & 6,154 & 296 & 3,610 & 173 \\
\hline Total & 5,692 & 4,900 & 3,453 & 2,973 \\
\hline
\end{tabular}

* Includes transportation, costs for caregiving and complementary and alternative medicine
Table 4. Lost Days and Morbidity Costs According to Cancer Site

\begin{tabular}{|c|c|c|c|c|}
\hline \multirow[t]{2}{*}{ Cancer Site } & \multicolumn{2}{|c|}{ Lost days* } & \multicolumn{2}{|c|}{ Morbidity costs $\dagger$} \\
\hline & $\begin{array}{c}\text { Per } \\
\text { patient }\end{array}$ & Total & $\begin{array}{c}\text { Per } \\
\text { patient }\end{array}$ & $\begin{array}{c}\text { Total } \\
\text { (millions) }\end{array}$ \\
\hline Stomach & 28.7 & $4,456,485$ & 5,237 & 814 \\
\hline Lung & 47.9 & $2,359,968$ & 4,442 & 219 \\
\hline Liver & 40.4 & $1,958,273$ & 6,821 & 330 \\
\hline Colon and rectum & 32.9 & $3,923,829$ & 4,752 & 566 \\
\hline Breast & 27.0 & $2,378,196$ & 4,131 & 364 \\
\hline Cervix uteri & 25.6 & 875,649 & 3,677 & 126 \\
\hline Thyroid & 20.9 & $2,864,007$ & 5,051 & 692 \\
\hline Gallbladder & 45.6 & 607,658 & 3,868 & 52 \\
\hline Pancreas & 54.6 & 460,581 & 4,809 & 41 \\
\hline Bladder & 31.5 & 625,978 & 4,454 & 89 \\
\hline Prostate & 34.7 & $1,032,450$ & 3,251 & 97 \\
\hline Kidney & 29.2 & 512,540 & 6,190 & 109 \\
\hline Esophagus & 46.4 & 300,411 & 5,015 & 32 \\
\hline Ovary & 35.6 & 377,512 & 3,859 & 41 \\
\hline Leukemia & 42.0 & 509,882 & 5,113 & 62 \\
\hline Oral cavity & 32.1 & 227,239 & 5,854 & 41 \\
\hline Larynx & 32.9 & 224,069 & 5,082 & 35 \\
\hline Melanoma of skin & 38.1 & 77,139 & 4,873 & 10 \\
\hline \multicolumn{5}{|c|}{ Brain and central nervous system } \\
\hline & 51.6 & 380,903 & 5,985 & 44 \\
\hline \multicolumn{5}{|c|}{ Non-Hodgkin lymphoma } \\
\hline & 34.0 & 637,245 & 5,691 & 107 \\
\hline Hodgkin disease & 25.7 & 35,718 & 6,376 & 9 \\
\hline Multiple myeloma & 58.7 & 194,934 & 5,226 & 17 \\
\hline Testis & 14.7 & 21,622 & 8,463 & 12 \\
\hline Corpus uteri & 26.3 & 257,386 & 3,745 & 37 \\
\hline Nasopharynx & 38.4 & 87,004 & 7,946 & 18 \\
\hline Other pharynx & 45.3 & 132,833 & 6,441 & 19 \\
\hline Others & 35.2 & $1,691,073$ & 4,448 & 214 \\
\hline Total & 31.6 & $27,210,579$ & 4,872 & 4,195 \\
\hline
\end{tabular}

* Length of stay+outpatient visit days/2; †Includes the employed and unemployed due to cancer 
Morbidity cost of cancer in Korea in 2009 amounted to $\$ 4,195$ million, or $\$ 4,872$ per patient (Table 4). Stomach cancer ranked the highest on total lost days, which are attributable to hospitalization and outpatient visits, and on morbidity cost with $\$ 814$ million.

Premature mortality from cancer is a significant factor that affects the productivity of an economy. In 2009, 72,544 individuals died from cancer alone in Korea (Table $5)$. It is equal to a loss of $\$ 5,251$ million of future income foregone at $3 \%$ discount rate, or $\$ 72,380$ per death, and

Table 5. Number of Deaths, Person-years Lost, and Mortality Costs, according to Cancer Site

\begin{tabular}{|c|c|c|c|c|}
\hline \multirow[t]{2}{*}{ Cancer Site } & \multirow{2}{*}{$\begin{array}{l}\text { No. of } \\
\text { deaths }\end{array}$} & \multirow{2}{*}{$\begin{array}{c}\text { Life } \\
\text { yrs lost } \\
\text { (per death) }\end{array}$} & \multicolumn{2}{|c|}{ Mortality costs* } \\
\hline & & & $\begin{array}{c}\text { Per } \\
\text { patient }\end{array}$ & $\begin{array}{c}\text { Total } \\
\text { (millions) }\end{array}$ \\
\hline Stomach & 11,360 & 17 & 72,835 & 827 \\
\hline Lung & 14,409 & 15.1 & 54,540 & 786 \\
\hline Liver & 11,681 & 19.8 & 104,800 & 1,224 \\
\hline Colon and rectum & 7,882 & 16 & 60,815 & 479 \\
\hline Breast & 1,847 & 29.2 & 88,170 & 163 \\
\hline Cervix uteri & 997 & 22.4 & 62,564 & 62 \\
\hline Thyroid & 654 & 18.1 & 62,192 & 41 \\
\hline Gallbladder & 3,235 & 14.8 & 47,323 & 153 \\
\hline Pancreas & 3,796 & 16.7 & 64,206 & 244 \\
\hline Bladder & 1,262 & 11.8 & 40,351 & 51 \\
\hline Prostate & 1,598 & 9.6 & 27,433 & 44 \\
\hline Kidney & 893 & 17.1 & 73,008 & 65 \\
\hline Esophagus & 1,472 & 15.1 & 59,972 & 88 \\
\hline Ovary & 799 & 24.9 & 68,601 & 55 \\
\hline Leukemia & 1,453 & 27.9 & 136,919 & 199 \\
\hline Oral cavity & 512 & 18.1 & 88,594 & 45 \\
\hline Larynx & 431 & 13.3 & 49,718 & 21 \\
\hline Melanoma of skin & 213 & 20.7 & 96,126 & 20 \\
\hline \multicolumn{5}{|c|}{ Brain and central nervous system } \\
\hline & 948 & 28.1 & 139,223 & 132 \\
\hline Non-Hodgkin lymphoma & 1,413 & 20 & 92,324 & 130 \\
\hline Hodgkin disease & 51 & 19.1 & 91,618 & 5 \\
\hline Multiple myeloma & 695 & 17.2 & 61,031 & 42 \\
\hline Testis & 17 & 38.83 & 322,618 & 5 \\
\hline Corpus uteri & 263 & 23.5 & 61,773 & 16 \\
\hline Nasopharynx & 196 & 24.1 & 148,128 & 29 \\
\hline Other pharynx & 405 & 15.5 & 63,403 & 26 \\
\hline Others & 4,062 & 17.5 & 72,873 & 296 \\
\hline Total & 72,544 & 17.3 & 72,380 & 5,251 \\
\hline
\end{tabular}

* Discounted at 3 percent

Table 6. Economic Costs of Cancer by Type of Cost

\begin{tabular}{|c|c|c|c|}
\hline Type of costs & $\begin{array}{l}\text { Per patient } \\
\text { (\$) }\end{array}$ & $\begin{array}{l}\text { Total } \\
\text { (\$ millions) }\end{array}$ & $\%$ \\
\hline Inpatient & 3,431 & 2,953 & 17.1 \\
\hline Outpatient & 1,614 & 1,390 & 8 \\
\hline Prescription drugs & 647 & 557 & 3.2 \\
\hline Subtotal(medical care costs) & 5,692 & 4,900 & 28.3 \\
\hline Caregiver time costs & 1,771 & 1,525 & 8.8 \\
\hline Transportation & 559 & 481 & 2.8 \\
\hline \multicolumn{4}{|c|}{ Complementary and alternative medicine } \\
\hline & 1,124 & 967 & 5.6 \\
\hline Subtotal(non-medical costs) & 3,453 & 2,973 & 17.2 \\
\hline Morbidity costs & 4,872 & 4,195 & 24.2 \\
\hline Mortality costs (discounted at 3\%) & b) 72,380 & 5,251 & 30.3 \\
\hline Total & 86,398 & 17,318 & 100 \\
\hline
\end{tabular}

*per death
DOI:http://dx.doi.org/10.7314/APJCP.2015.16.3.1295

Aspects of the Economic Burden of Cancer in Korea in 2009

Table 7. Sensitivity Analysis of Economic Costs of Cancer

\begin{tabular}{llll}
\hline Cost category & \multicolumn{2}{c}{ Subject group for calculating } & $\begin{array}{c}\text { Amount } \\
\text { (\$ millions) }\end{array}$ \\
\cline { 2 - 3 } Mortality costs & Discounted at 3\% & Applying 100\% & 5,251 \\
& & Applying 50\%* & 4,144 \\
& Discounted at 5\% & Applying 100\% & 4,471 \\
& & Applying 50\%* & 3,553 \\
Range of total economic costs $\dagger$ & $17,318 \sim 15,621$ & \\
\hline
\end{tabular}

$* 50 \%$ of the annual earnings of persons aged $60-64$ years were used for the aged ( 65 years or over). $†$ Include medical, non-medical and morbidity costs of 12,068 million dollar

17.3 life years of productivity lost per death. However, cancer mortality costs vary by cancer sites. Liver cancer ranked the highest, accounting for $23.3 \%$ of the total mortality costs, followed by stomach cancer (15.8\%). On the other hand, mortality cost per patient was the highest in testis cancer, followed by nasopharyngeal caner, brain cancer, and leukemia.

Total economic cost of cancer was estimated at $\$ 17,318$ million in Korea in 2009 (Table 6). Medical care costs, non-medical costs, morbidity cost, and mortality cost were $28.3 \%, 17.2 \%, 24.2 \%, 30.3 \%$ of the total cost, respectively. Result of the sensitivity analysis is shown in Table 7. Mortality costs ranged from $\$ 3,553$ million to $\$ 5,251$ million.

\section{Discussion}

The result of our study suggests that cancer is still a costly disease in Korea, accounting for over $\$ 17.3$ billion of economic burden in 2009. Stomach cancer was identified as the single most costly cancer, with nearly $\$ 3$ billion price tag. The six major categories of cancer: stomach, lung, liver, colorectal, breast, and cervix cancer, accounted for $61 \%$ of the total economic burden of cancer in Korea in 2009. In 2002 and 2005, economic burden of cancer was $\$ 9,417$ million and $\$ 14.0$ billion, respectively (Kim et al., 2008; Kim et al., 2009). Although the rate of increase in the cancer care cost has slowed down, it still imposes a substantial economic burden on society. Especially, direct cost and morbidity cost of cancer were on the increase, although mortality cost decreased over the last decade. Medical care cost, which accounted for $13.7 \%$ of the overall cost in 2002, was about third of the cancer burden in this study. This rapid increase is owed to an increase in cancer incidence, new indications for treatment with previously approved cancer drugs and to placement of new drugs on the market (Mariotto et al., 2011; Sullivan et al., 2011; Wani et al., 2013; Peixoto et al., 2014). Emerging trends of substituting surgeries with noninvasive/low-toxicity approaches and conventional radiotherapy with IMRT may also have driven up the medical care costs. Recently EU reported the total cost of cancer to be $€ 126$ billion in 2009 , of which $€ 51.0$ billion was incurred by medical cost (Luengo-Fernandez et al., 2013). In the USA, the cost of cancer was estimated at US $\$ 212.6$ billion in 2009 , of which $\$ 86.6$ billion was direct medical cost and $\$ 130.0$ billion was mortality cost (American Cancer Society, 2014). In both studies, medical 
costs accounted for nearly $40 \%$ of the overall economic burden, which is roughly $10 \%$ higher than our study result. However, hospital inpatient care in the EU study accounted for more than half of medical cost, which is comparable to the result of this study. The Korean government invested tremendous budget between 2005 and 2009 to decrease cancer patients' burden for medical costs. However, outof-pocket cancer care cost still remains high due to strong presence of non-insured or partially insured medical costs. This financial burden can cause substantial distress, sometimes forcing patient to give up the optimal treatment. Therefore, considering steep increase and relatively low portion of medical cost in the overall cancer burden, evidence-based monitoring for medical cost as well as an effort for expanding limited benefits are needed. It has been pointed out that unnecessary testing and unproven medical procedures were the major factors of an increase in medical costs (Furlow, 2012). Discussing out-of-pocket costs between physician and patient is also important to choose alternative treatments that are less expensive but equally or nearly as effective (Ubel et al., 2013; Morden et al., 2014).

The increase of medical cost also led to corresponding increase of the non-medical costs. Especially, costs associated with informal or formal caregiving have grown substantially. Thus, in addition to reducing the treatment expenses, an effort to decrease the caregiving expenses is much needed. Family caregivers also report considerable distress that may interfere with their ability to provide emotional or logistical support and exacerbate patients' emotional distress (Braun et al., 2007; IOM, 2013). Thus, in the future cancer care setting, it is especially important for the care team to identify the psychosocial health needs of patients and their families, and to develop a care plan that addresses these needs.

Over the last decade, mortality cost has constituted the overwhelming majority of the total productivity loss. As mentioned above, estimated cancer-related premature mortality costs were declining but still substantial, accounting for a third of the overall cancer burden. Number of death, age at diagnosis and survival all impact the mortality costs. In particular, cancers with earlier age at onset and that have moderate or poor prognosis, tend to rank more highly in terms of costs (Hanly and Sharp, 2014). Contrary to the previous results, morbidity costs occupy a larger portion of total costs. This leads to excess health care expenditures. Multifaceted prevention strategies including research, education, policy change, and sustained intervention programs may help reduce the economic impact of cancer (Guy et al., 2013).

This study is performed in line with previous nationwide researches (Kim et al., 2008; Kim et al., 2009). Key strengths of the study include the use of population data and comprehensive coverage of the component of cancer burden. Nevertheless, there are some limitations. First, in order to enhance the comparability of our results, we used similar method with the previous study (Kim et al., 2008), granting this study comparable limitations. For example, categories of cost for low quality of life, psychological morbidity, sexuality, and the pain of patient were omitted from this study. Second, the cost of CAM was measured using the survey conducted at a single hospital due to lack of reliable data, thus somewhat limiting generalizability of the result. Third, since we measured cancer cost based on prevalence, we were not able to estimate the lifetime cost of cancer. Last, the human capital approach undervalues some groups, such as children, women and the retired elderly; this is because this approach estimates costs from market activities that put greater weight on older and working male compared to younger person. Nevertheless, the human capital approach is widely used throughout the economic literature and used to enhance the comparability of this study.

In conclusion, this study estimated the economic costs attributed to cancer in Korea in 2009 using the nationwide database. Given that the direct medical cost sharply increased over the last decade, we must strive to construct a sustainable health care system that provides better care while lowering the cost. In addition, comprehensive cancer survivorship policy aimed at lower caregiving cost and higher rate of return to work has become more important than before.

\section{References}

American Cancer Society (2014). Cancer facts and figures 2014. Braun M, Mikulincer M, Rydall A, et al (2007). Hidden morbidity in cancer: spouse caregivers. J Clin Oncol, $\mathbf{2 5}$, 4829-34.

Byun JY, Yoon SJ, Oh IH, et al (2014). Economic burden of colorectal cancer in Korea. J Prev Med Public Health, 47, 84-93.

Choi JW, Cho KH, Choi Y, et al (2014). Changes in economic status of households associated with catastrophic health expenditures for cancer in South Korea. Asian Pac J Cancer Prev, 15, 2713-7.

Drummond MF, Sculpher MJ, Torrance GW, et al (2005). Methods for the Economic Evaluation of Health Care Programmes. OUP Catalogue.

Furlow B (2012). Expensive US cancer care: value for money? The Lancet Oncology, 13, 193.

Grunfeld E, Coyle D, Whelan T, et al (2004). Family caregiver burden: results of a longitudinal study of breast cancer patients and their principal caregivers. Canadian Med Assoc $J, \mathbf{1 7 0}, 1795-801$.

Guy GP Jr, Ekwueme DU, Yabroff KR, et al (2013). Economic burden of cancer survivorship among adults in the United States. J Clin Oncol, 31, 3749-57.

Hanly PA, Sharp L (2014). The cost of lost productivity due to premature cancer-related mortality: an economic measure of the cancer burden. BMC Cancer, 14, 224.

IOM (Institute of Medicine) (2013). Delivering high quality cancer care: Charting a new course for a system in crisis. Washington, DC: The National Academies Press.

Jemal A, Bray F, Center MM, et al (2011). Global cancer statistics. CA: A Cancer J Clin, 61, 69-90.

Jung KW, Park S, Kong HJ, et al (2012). Cancer statistics in Korea: incidence, mortality, survival, and prevalence in 2009. Cancer Res Treat, 44, 11-24.

KCDC (Korea Centers for Disease Control \& Prevention) (2009). national health and nutrition examination survey in 2009.

Kim J, Hahm MI, Park EC, et al (2009). Economic burden of cancer in South Korea for the year 2005. J Prev Med Public Health, 42, 190-8.

Kim SG, Hahm MI, Choi KS, et al (2008). The economic burden of cancer in Korea in 2002. Eur J Cancer Care, 17, 136-44. 
Kim SY, Chang YJ, Do YR, et al (2013). Employment status and work-related difficulties among family members of terminally Ill patients compared with the general population. Asian Pac J Cancer Prev , 14, 373-9.

KNHIC (Korea Natioanal Health Insurance Corporation) (2009). National Health Insurance Statistical Yearbook.

KNIHC (Korea Natioanal Health Insurance Corporation) (2010). Health Insurance Patients Payments Survey 2009.

KPHS (Korea Patient Helper Society). Available from: http:// www.help114.or.kr/.

Ministry of Labor (2009). Survey Report on Wage Structure in 2009.

Luengo-Fernandez R, Leal J, Gray A, et al (2013). Economic burden of cancer across the European Union: a populationbased cost analysis. The Lancet Oncology, 14, 1165-74.

Mariotto AB, Yabroff KR, Shao Y, et al (2011). Projections of the cost of cancer care in the United States: 2010-2020. $J$ Natl Cancer Inst, 103, 117-28.

Morden NE, Colla CH, Sequist TD, et al (2014). Choosing wisely-the politics and economics of labeling low-value services. New Engl J Med, 370, 589-92.

Park JH, Park EC, Park JH, et al (2008). Job loss and reemployment of cancer patients in Korean employees: a nationwide retrospective cohort study. J Clin Oncol, 26, 1302-9.

Peixoto V, Faria AL, Goncalves M, et al (2014). Evolution of costs of cancer drugs in a Portuguese hospital. World J Clin Oncol, 5, 164-9.

Shin JY, Kim SY, Lee KS, et al (2012). Costs during the first five years following cancer diagnosis in Korea. Asian Pac $J$ Cancer Prev, 13, 3767-72.

Sullivan R, Peppercorn J, Sikora K, et al (2011). Delivering affordable cancer care in high-income countries. Lancet Oncol, 12, 933-80.

Tachfouti N, Belkacemi Y, Raherison C, et al (2012). First data on direct costs of lung cancer management in Morocco. Asian Pac J Cancer Prev, 13, 1547-51.

Turkoglu N, Kilic D (2012). Effects of care burdens of caregivers of cancer patients on their quality of life. Asian Pac J Cancer Prev, 13, 4141-5.

Ubel PA, Abernethy AP, Zafar SY (2013). Full disclosure-out-ofpocket costs as side effects. New Engl J Med, 369, 1484-6.

Wani MA, Tabish SA, Jan FA, et al (2013). Cost analysis of in-patient cancer chemotherapy at a tertiary care hospital. $J$ Cancer Res Ther, 9, 397-401.

Wissinger E, Griebsch I, Lungershausen J, et al (2014). The economic burden of head and neck cancer: a systematic literature review. Pharmacoeconomics, 32, 865-82.

Yabroff KR, Lawrence WF, Clauser S, et al (2004). Burden of illness in cancer survivors: findings from a population-based national sample. J Natl Cancer Inst, 96, 1322-30.

Yang SC (2013). Estimating the lifelong health impact and financial burdens of different types of lung cancer. $B M C$ Cancer, 13, 579.

You CH, Kang S, Kwon YD, Choi JH (2013). Time trend of out-of-pocket expenditure among cancer inpatients: evidence from Korean tertiary hospitals. Asian Pac J Cancer Prev, 14, 6985-9. 